\title{
The Dietitian Role and Nutritional Status of Benghazi Cancer Patients
}

\author{
Faiza Nouh*, Salima Elfagi, Mariam Omar
}

Department of Nutrition, Faculty of Public Health, Benghazi University, Benghazi, Libya

DOI: $10.36347 /$ sajb.2020.v08i04.004

| Received: 19.02 .2020 | Accepted: 26.02.2020 | Published: 14.04 .2020

*Corresponding author: Faiza Nouh

Abstract

Original Research Article

Clinical studies show that nutritional intervention is effective to prevent malnutrition in cancer patients undergoing chemotherapy and/ or radiotherapy. The objective of the present study was to assess the value of counselling by a dietitian compared to standard nutritional care. A cross-sectional study, conducted between 2015 and 2017, compared individual dietary counselling, BMI, and nutritional status. Endpoints were weight loss, BMI and malnutrition. Only $(52 \%)$ of the subjects had normal BMI. When comparing nutritional status of the subjects according to nutritional counselling provider; subjects who receive their special diet counselling for cancer from dietitians had better nutritional status than those who receive standard medical care. Therefore, early and intensive individualised dietary counselling by a dietitian produces clinically relevant effects in terms of decreasing weight loss and malnutrition compared with standard medical care in cancer patients.

Keywords: Dietitian, Nutritional Status, Cancer Patients.

Copyright @ 2020: This is an open-access article distributed under the terms of the Creative Commons Attribution license which permits unrestricted use, distribution, and reproduction in any medium for non-commercial use (NonCommercial, or CC-BY-NC) provided the original author and source are credited

\section{INTRODUCTION}

Cancer is reported to be the second and third leading cause of all deaths in developed and developing countries including Libya. Malnutrition is a substantial problem among Benghazi cancer patients. The most common treatments for these patients include surgery, radiotherapy, chemotherapy or a combination of these managements. The risk of nutritional deterioration is increased during the initiation, prognosis and actual treatment of cancer [1-3].

Cancer and its treatment induce morbidity; symptoms such as mucositis, impaired swallowing function, declined eating ability, xerostomia, dysgeusia, nausea and vomiting may limit oral intake, and inevitably result in unintended weight loss during radiotherapy and for a prolonged period after the treatment. Nutritional depletion in these patients reduces their tolerance to treatment. Malnutrition in cancer patients was significantly correlated with an increased risk of infections in patients undergoing surgery and the occurrence of major postoperative complications $[4,5]$.

In addition, higher mortality and morbidity rates, shorter failure-free survival and poorer quality of life. More specifically, unintended weight loss was found to be associated with a higher rate of cancer patients. It is therefore important to maintain an optimal nutritional status for patients through nutritional intervention during oncological treatment. Several studies suggested that early and intensive nutritional intervention during and after treatment of cancer patients may be beneficial in terms of decreasing the impact of side effects, decreasing unintended weight loss, and improving dietary intake, quality of life and treatment tolerance $[6,7]$.

Although many studies demonstrate the benefits of full nutritional intervention programme, including dietary counselling, there is little evidence for the potential added value of a professional dieticians' support. Nutritional care of cancer patients undergoing at Benghazi centre has traditionally been managed as a part of medical management with limiting opportunity for multidisciplinary collaboration [8]. Cancer cachexia, affecting as much as two-third of all cancer patients, it is a complex syndrome that results in severe wasting of lean body mass, weight loss and malnutrition. These effects result in poor food intake, increased nutrient and energy needs and more catabolism. Continuing weight loss ensues [9]. The extent of these effects may vary widely from mild response to an extreme form of debilitating cachexia. Conversely anorexia leading to poor food intake may also be a contributing factor of gross malnutrition of cancer cachexia by setting up a vicious cycle of malnutrition, if not timely and suitably counteracted. At times, cachexia may become more immediately life threatening than the local effects of 
cancer itself. It is reported that cancer cachexia is responsible for more deaths than cancer itself. Because malnutrition alone can lead to an increased risk of complications and lower quality of life, it is essential that malnutrition is recognized early. Wise and early use of vigorous nutritional support for cancer patients has been shown to provide recovery of normal nutritional status, including immunocompetence, thus improving their response to therapy and prognosis [10-12]. Nutrition therapy, when indicated, should be indicated early; by providing early nutritional support, it is possible to prevent or delay deterioration in the patient's nutritional status. It is far easier to maintain nutrition from the beginning than to rebuild the body from extreme malnutrition. Malnutrition related to cancer cachexia is easier to prevent than to treat, justifying the need for initiation of early nutritional support before the spiral of malnutrition develops. The dietitian plays a leadership role in improving the quality of life of cancer patients. A better understanding of this role can strengthen practice in this area $[13,14]$.

Subjective Global Assessment (SGA) and the Patient Generated -Subjective Global Assessment (PGSGA) are the only malnutrition screening tools that are recommended by the ASPEN Board of Directors for a routine clinical use [15]. Although there is high prevalence of death due to cancer in Libya, there is very limited number of research on cancer in Libya [6]. Moreover, very limited number of research had used (PG-SGA) in Libya as well as in Arabic countries [8]. The present study was designed to evaluate the effect of dieticians' role on nutritional status of Benghazi cancer patients. The objective was to investigate whether individualised dietary counselling by a dietitian would better maintain a patient's body weight, and thus prevent malnutrition compared to standard medical care.

\section{MATERIALS AND METHODS Methodology Subjects}

A cross-sectional study was carried out from 10th March 2015 to 30th August 2017 on cancer patients in Benghazi city attending Benghazi Medical Center (BMC). Study has stopped for some time due to the war condition in Benghazi. Initially 462 cancer patients were randomly approached between $1^{\text {st }}$ August 2015 and $30^{\text {th }}$ March 2017 (period of data collection) to participate in the study. Out of 462 patients who were deemed fit to participate in the study, 29 refused to participate in the study and 33 patients dropped out from the study or were excluded because of incomplete or implausible data. A total of 400 cancer patients (out of the 462 possible study recruits) comprising 111 males and 289 females, with complete questionnaires with clearly filled up entries were finally enrolled in the study giving a response rate of $(86.58) \%$. The inclusion criterion for enrolment in the present study was all oncology patients who were receiving radiotherapy and/ or chemotherapy and had a body weight record for the previous two weeks and one month. In case the previous six months body weight was not available then a record taken one month back was acceptable.

\section{DATA COLLECTION}

Data was collected by trained dieticians. To avoid subjective bias data collectors underwent training sessions on interviewing skills, anthropometry measurements and data entering, and coding at Department of Nutrition, Benghazi University. A small pilot study was carried out and 10 questionnaires were tested from $15^{\text {th }}$ to $20^{\text {th }}$ July 2017 to test questionnaire and feasibility of study methods.A detailed structured interview based questionnaire was prepared for collecting information about the studied subjects. The questionnaire collected information regarding select socio-economic characteristics, dietary information and anthropometric measurements. The questionnaire was reviewed before being translated in Arabic, the local language. The questionnaire was divided into various sub-sections. The first section covered various characteristics like preliminary information: age, gender, nationality, marital status, family information, monthly family income and its self perceived adequacy to purchase nutritious food. Living conditions include type of housing and food preparation. A detailed information was collected regarding the type of cancer, duration of cancer (date of the first diagnosis), type of cancer therapy followed and its duration. It also contained sub-sections for collecting information regarding by who provided nutritional care and counselling. Subjects were also questioned if they were prescribed a special oncology diet and for those who answered in the affirmative there were additional questions like which it was prescribed by and its compliance. Height and weight measurements were used to calculate Body Mass Index (BMI). Anthropometric measurements were the taken in a private area using standard techniques as recommended by the World Health Organisation (WHO) [15]. The final nutritional status of patients was assessed by Patient Generated -Subjective Global Assessment.

\section{Ethical Approval}

Informed consent was obtained from the subjects who were also assured of the confidentiality of the information collected. The research was approved by the administration of the concerned hospital and University of Benghazi. Prior to the start of the project the respective hospital administration were informed in writing about the aim of the study to obtain the maximum possible cooperation to conduct the study.

\section{STATISTICAL ANALYSIS}

All data was coded prior to being entered into a computer. Description and analysis of data were carried using SPSS version 21. Chi Square was used to test the association between two qualitative variables. Level of significance was set at $\mathrm{p}$ value $<0.05$. Chi Square was 
used to test the association between two qualitative variables. Independent t-test between a qualitative and a quantitative variable. Bivariate correlation was carried out to test the relationships between quantitative variables

\section{THE RESULTS}

The total studied sample of 400 cancer patients, $27.8 \%(\mathrm{n}=111)$ were males with females $(\mathrm{n}=289)$ representing $72.2 \%$ of the total sample. Means age \pm SD was 52.8 years \pm 11.5 . More than half of the subjects $(58 \%)$ aged between $40-59$ years old. BMI of the subjects was varied with $(34.2 \%$ and $36.5 \%)$ for under-weight and obese respectively. The most common cancer among male was colon (40.5\%), while among female was breast cancer $(38.6 \%)$. $(80 \%)$ of the subjects do not follow any cancer diet. Among those who follow special diet for cancer; $(60 \%)$ of the subjects received their dietary advice and prescription from the physicians rather than dietitians. Among those who follow special cancer diet $(88 \%)$ were fully complained with their diet. Only $(52 \%)$ of the subjects had normal BMI; while (34.25) of the subjects were underweight. Only (13.75\%) of the subjects were overweight. When comparing nutritional status of the subjects according of care nutritional counselling provider; subjects who receive their special diet counselling for cancer from dietitians had better nutritional status than those who receive standard medical care and take their advice from physicians as shown in table 2. Furthermore, BMI values of subjects who follow a diet prescribed by dietitian were better than those who receive standard medical care and take their advice from physicians as shown in table 3.

Table-1: Subject characteristics

\begin{tabular}{|c|c|c|c|}
\hline \multirow[t]{2}{*}{ Variables } & \multicolumn{2}{|c|}{ Sex } & \multirow[t]{2}{*}{ Total } \\
\hline & Male & Female & \\
\hline Age & $20(5)$ & $45(11.25)$ & $65(16.25)$ \\
\hline $20-39$ & $61(15.25)$ & 171(42.75) & 232(58) \\
\hline $40-59$ & $30(7.5)$ & 73(18.25) & $103(25.75)$ \\
\hline$\geq 60$ & $50.1 \pm 2.3$ & $54.1 \pm 1.2$ & $52.8 \pm 11.5$ \\
\hline \multicolumn{4}{|l|}{ Mean \pm SD } \\
\hline Libyan & $80(72)$ & $200(69.2)$ & $304(76)$ \\
\hline Others & $31(28)$ & $89(30.8)$ & $96(24)$ \\
\hline \multicolumn{4}{|l|}{ Cancer Type } \\
\hline Colon & $45(40.5)$ & $79(27.3)$ & $124(67.8)$ \\
\hline Lung & $30(27)$ & 0 & $30(27)$ \\
\hline Breast & 0 & $112(38.6)$ & $112(38.6)$ \\
\hline Prostrate & $20(18)$ & 0 & $20(18)$ \\
\hline Ovary \& uterus & 0 & $68(23.5)$ & $68(23.5)$ \\
\hline Others & $16(11)$ & $30(10.4)$ & $46(21.4)$ \\
\hline \multicolumn{4}{|l|}{ Type of cancer therapy } \\
\hline $\mathrm{CT} *$ & $83(74.7)$ & $212(73.4)$ & $295(73.75)$ \\
\hline $\mathrm{RT} * *$ & $17(15.4)$ & $45(15.6)$ & $62(15.5)$ \\
\hline Both & $11(9.9)$ & $32(11.0)$ & $43(10.75)$ \\
\hline \multicolumn{4}{|l|}{ Duration of therapy (months) } \\
\hline$<6$ & $68(61.5)$ & $162(56)$ & $230(57.5)$ \\
\hline $6<12$ & $26(23.1)$ & $74(25.7)$ & $100(25)$ \\
\hline $12<24$ & $12(11.0)$ & $42(14.7)$ & $54(13.5)$ \\
\hline$\geq 24$ & $5(4.4)$ & $11(3.7)$ & $16(4)$ \\
\hline $\mathrm{Me}-\bar{a} \overline{\mathrm{SD}}$ & $6.2 \pm 6.2$ & $7.5 \pm 12.6$ & $6.9 \pm 10.2$ \\
\hline \multicolumn{4}{|l|}{ Cancer diet } \\
\hline Yes & $47(11,75)$ & $73(18.25)$ & $120(20)$ \\
\hline No & $64(16)$ & $216(54)$ & $280(80)$ \\
\hline \multicolumn{4}{|l|}{ Diet prescribed by } \\
\hline Physician & 30 & 55 & $85(60)$ \\
\hline Dietician & 17 & 18 & $35(40)$ \\
\hline \multicolumn{4}{|l|}{ BMI } \\
\hline Underweight & $39(9.75)$ & $98(24.5)$ & $137(34.25)$ \\
\hline Normal & $51(12.75)$ & $167(39.25)$ & $208(52)$ \\
\hline Overweight or obese & $21(5.25)$ & $34(8.5)$ & $55(13.75)$ \\
\hline \multicolumn{4}{|l|}{ Diet compliance } \\
\hline Yes & $25(6.25)$ & $81(20.25)$ & $106(88)$ \\
\hline No & $11(2.75)$ & $3(0.75)$ & $14(12)$ \\
\hline Nutrition status & $20(5)$ & $28(7)$ & $48(12)$ \\
\hline Well nourished & $55(13.75)$ & $93(23.25)$ & $148(37)$ \\
\hline $\begin{array}{c}\text { Moderately or suspected malnourished } \\
\text { Severely malnourished }\end{array}$ & $36(9)$ & $168(42)$ & $204(51)$ \\
\hline
\end{tabular}

* RT: Radiotherapy ** CT: Chemotherapy 
Table-2: Association between nutritional status and source of diet prescription

\begin{tabular}{|l|c|c|c|}
\hline Source of diet prescription & \multicolumn{3}{|c|}{ Nutrition status } \\
\cline { 2 - 4 } & Well nourished & Risk to malnutrition & Severely malnourished \\
\hline Standard medical care & 33 & 27 & 50 \\
Dietitian care & 51 & 25 & 24 \\
\hline
\end{tabular}

Table-3: Association between BMI and source of diet prescription

\begin{tabular}{|l|c|c|c|}
\hline Source of diet prescription & \multicolumn{3}{|c|}{ BMI } \\
\cline { 2 - 4 } & Under-weight & Normal & Overweight \\
\hline Standard medical care & 37 & 33 & 30 \\
Dietitian care & 31 & 36 & 33 \\
\hline
\end{tabular}

\section{DISCUSSION}

Nutritional support often involves recommendations and provisioning of nutrient-dense food and supplements. Energy intake increases when patients receive supplements. In the literature, the prevalence of malnutrition is associated with higher mortality and morbidity rates, shorter failure-free survival and poorer quality of life among cancer patients [16].

It is therefore essential to control unintended weight loss/malnutrition and maintain an efficient nutritional status for cancer patients. The present study tries to demonstrate the beneficial effect of diet prescribed by dietitians on BMI and malnutrition for Benghazi cancer patients rather than standard medical care only. The results of the current study indicate that dieticians' role significantly contributes to maintaining and improving weight loss and malnutrition of cancer patients. This is an important clinically relevant finding which confirms the research objective of the present study.

A randomised study performed by Ravasco et $a l$. produced similar results. The study demonstrated that individualised dietary counselling (based on regular foods) for cancer patients undergoing radiotherapy is the most effective way of improving patients' nutritional intake, nutritional status and quality of life [17]. An another randomised controlled trial by Isenring et al. showed that dietary counselling using the American Dietetic Association - Medical Nutrition Therapy oncology protocol resulted in a significant reduction in unintended weight loss from the start of radiotherapy until 3 months after the treatment compared with their standard practice (which consisted of general nutritional advice by a physician, a nurse and a booklet) [18].

Furthermore, the present study revealed an improvement in nutritional, dietary intake and quality of life in the dietary counselling group when compared with the standard practice. It is interesting to note that while there have been only a handful of studies in this area by different research teams; they all have demonstrated benefits of dietary counselling like the present study.
Accordingly, early and intensive dietary counselling produces clinically significant effects in terms of decreasing unintended weight loss and malnutrition compared with standard medical care in cancer patients. In clinical practice, patients should receive regular and individualised dietary counselling from diagnosis until after radiotherapy, chemotherapy and surgery as long as possible.

\section{ACKNOWLEDGEMENTS}

All authors hereby declare that no financial or personal interest is involved which may bias or influence the present study. All authors contributed to the concept and design of the present study, acquisition, analysis and interpretation of data. All authors approved the final version of the present manuscript.

\section{REFERENCES}

1. Nouh F, Omar M, Younis M, Younis M, Mohamed R, Gaith R, Reyad W. Nutritional status of lung cancer patients in Benghazi City of Libya. Journal of Cancer and Tumor International. 2017;6(3):1-10.

2. Aktas A, Walsh D, Galang M, O’Donoghue N, Rybicki L, Hullihen B, Schleckman E. Underrecognition of malnutrition in advanced cancer: the role of the dietitian and clinical practice variations. American Journal of Hospice and Palliative Medicine ${ }^{\circledR} .2017$ Jul;34(6):547-55.

3. Nouh F, Omar M, Alshukri A, Younis M, Elmabsout A, Salem M, Awad E, Mari R, Hassan R. Nutritional status of female breast cancer patients in Benghazi City of Libya. Scholars Journal of Applied Medical Sciences. 2017;5(6B):2179-2187.

4. Aktas A, Walsh D, Galang M, O’Donoghue N, Rybicki L, Hullihen B, Schleckman E. Underrecognition of malnutrition in advanced cancer: the role of the dietitian and clinical practice variations. American Journal of Hospice and Palliative Medicine®. 2017 Jul;34(6):547-55.

5. James- Martin G, Koczwara B, Smith EL, Miller MD. Information needs of cancer patients and survivors regarding diet, exercise and weight management: a qualitative study. European journal of cancer care. 2014 May;23(3):340-8.

6. Nouh F, Mekraz EI, Omar M, Younis M, Younis M. Diet of Benghazi Cancer Patients; Quality and 
Associated Factors. Journal of Cancer and Tumor International. 2018 Feb 8:1-4.

7. Monnin S, Schiller MR. Nutrition counseling for breast cancer patients. Journal of the American Dietetic Association (USA). 1993.

8. Omar M, Nouh F, Younis M, Elmabsout A. Weight Change during Hospitalization: Recognition of Risk Factors. Prospective Study at Benghazi Medical Center. Journal of Advances in Medicine and Medical Research. 2017 Sep 20:1-3.

9. Tisdale MJ. Mechanisms of cancer cachexia. Physiological reviews. 2009 Apr;89(2):381-410.

10. Kern KA, Norton JA. Cancer cachexia. Journal of Parenteral and Enteral Nutrition. 1988 May;12(3):286-98.

11. Fearon K, Strasser F, Anker SD, Bosaeus I, Bruera E, Fainsinger RL, Jatoi A, Loprinzi C, MacDonald N, Mantovani G, Davis M. Definition and classification of cancer cachexia: an international consensus. The lancet oncology. 2011 May 1;12(5):489-95.

12. Argilés JM, Busquets S, Stemmler B, López-Soriano FJ. Cancer cachexia: understanding the molecular basis. Nature Reviews Cancer. 2014 Nov;14(11):754-62.

13. Blot WJ, Li JY, Taylor PR, Guo W, Dawsey S, Wang GQ, Yang CS, Zheng SF, Gail M, Li GY, Yu Y. Nutrition intervention trials in Linxian, China: supplementation with specific vitamin/mineral combinations, cancer incidence, and disease-specific mortality in the general population. JNCI: Journal of the National Cancer Institute. 1993 Sep 15;85(18):1483-91.

14. Capra S, Ferguson M, Ried K. Cancer: impact of nutrition intervention outcome-nutrition issues for patients. Nutrition. 2001 Sep 1;17(9):769-72.

15. Nouh F, Omar M, Younis M. Prevalence of Hypertension among Diabetic Patients in Benghazi: A Study of Associated Factors. Asian Journal of Medicine and Health. 2017 Aug 31:1-1.

16. Van den Berg MG, Rasmussen-Conrad EL, Wei KH, Lintz-Luidens H, Kaanders JH, Merkx MA. Comparison of the effect of individual dietary counselling and of standard nutritional care on weight loss in patients with head and neck cancer undergoing radiotherapy. British journal of nutrition. 2010 Sep;104(6):872-7.

17. Ravasco P, Monteiro- Grillo I, Marques Vidal P, Camilo ME. Impact of nutrition on outcome: a prospective randomized controlled trial in patients with head and neck cancer undergoing radiotherapy. Head \& Neck: Journal for the Sciences and Specialties of the Head and Neck. 2005 Aug;27(8):659-68.

18. Isenring EA, Capra S, Bauer JD. Nutrition intervention is beneficial in oncology outpatients receiving radiotherapy to the gastrointestinal or head and neck area. British journal of cancer. 2004 Aug;91(3):447-52. 